\title{
Instability and advanced models for coupled phenomena in geomechanics and applied sciences: a tribute to Félix Darve
}

Published online: 2 September 2014

(C) Springer-Verlag Berlin Heidelberg 2014

We are pleased to announce that this special issue in honor of Professor Félix Darve finally arrives to its conclusion, and we think to have fully reached the goal of collecting papers of high scientific quality coming from outstanding colleagues of Félix.

Some of the selected papers come from scientists who have been directly connected to Félix during their career, some of them from his former students who now have reached high scientific recognitions, and some others from scientists who work on subjects related to those approached by Félix during his scientific career and who recognize Félix's important contributions to science.

We personally feel grateful to Félix for his lessons of life and science that he gave us in different occasions of our lives and that made possible our personal and scientific realization.

This special issue is the best way we found to thank him and to celebrate his 65 th birthday.

We could spend a lot of words to discuss Félix's merits, but we think that the "laudatio" which has been written in occasion of the delivery of the "Tullio Levi-Civita" prize to Félix is undoubtedly the best summary of his scientific weight. For this reason, we report the integral text of the "laudatio" in the remainder of this editorial and we thank once again Félix for his outstanding scientific and personal contributions.

Félix Darve is the author of more than 200 papers. His contribution has been primarily directed to the goal of establishing the basis of geomechanics, academic discipline of which he was among the founders in an international scale, in the early 1980s. The Geomechanics is now a discipline of broad interest and the subject of several international journals and several series of international conferences. The geomechanics aims to apply the tools and methods of mechanics to the study of soils, rocks and cement, grouped under the general category of "geomaterials" because of the many features that distinguish them from solid materials.

Felix Darve was born on 1947. He graduated in engineering from the Ecole Centrale in Paris in July 1971, and he defended his PhD in the University of Grenoble in 1974 and the Doctorat des Sciences in 1978 in the field of numerical modeling of geomaterials. He began his academic career as an assistant at the University of Grenoble, and then as maitre-assistant at the Institut Polytechnique of Grenoble. In 1985 he was appointed professor and he received in 1998 the promotion to the exceptional class from the Comité National des Universites.

During his career, Felix Darve covered positions of great responsibility both locally and nationally. He founded and directed the Groupement de Recherches Coordonnées (GRECO) "Géomatériaux" of the CNRS

A. Madeo

Laboratoire de Génie Civil et Ingénierie Environnementale (LGCIE), Institut National des Sciences Appliquées (INSA) de Lyon, Bâtiment Coulomb, 69100 Villeurbanne, France

E-mail: angela.madeo@insa-lyon.fr

F. Nicot $(\varangle)$

Geomechanics Group, Unité de Recherche Erosion Torrentielle Neige et Avalanches, Irstea - Grenoble, Domaine Universitaire, BP 76, 38402 Saint Martin d'Hères Cedex, France

E-mail: francois.nicot@irstea.fr 
(Centre National des Recherches) from 1986 to 1993. The GRECO, with its 250 members, contributed to organize and finance the French research in geomechanics. From 1987 to 1992, he directed the Ecole Nationale Supérieure de Mécanique et d'Hydraulique of Grenoble. In 1989, he founded the network of "European laboratories' ALERT Geomaterials," where he covered the chair of president until 2011. This Network of Excellence is today, together with its 25 laboratories, a point of reference for the geomechanics European community. ALERT has contributed to the beginning of a European school of thought in the field of geomechanics. From 1992 to 1995, he was Deputy Director of the Department at the French Ministry of Research that is responsible for monitoring all laboratories in the areas of solid mechanics, civil engineering and mechanical engineering. Felix Darve has chaired numerous scientific committees, evaluation committees, and research facilities. He serves as an expert in international organizations.

As for his editorial responsibilities, in addition to its participation as a member of the editorial board of several international journals (Granular Matter, Computers and Geotechnics, CRAS Mecanique, MeMOCS,...), he founded the "European Journal for Environmental and Civil Engineering" (EJECE, Taylor and Francis, indexed on ISI WoS) and "Mechanics of Cohesive-Frictional Materials" (MCFM, Wiley), which subsequently merged with the "International Journal for Numerical and Analytical Methods in Geomechanics" (IJNAMG, Wiley). It is currently one of the editors-in-chief of IJNAMG. In addition, Felix Darve was co-author of 14 books (Elsevier, Balkema, Hermes, Lavoisier,...). He is the author, with J. Berthier, of a report to the French Minister of Research.

The damage in geomaterials often occurs due to the formation of slip bands in which the plastic deformation concentrates, or due to fractures, especially of the type micro-cracking. Since 1976, F. Darve has recognized the importance of applying in geomechanics the concepts of bifurcation of deformation modes, with the aim of studying the localization of deformation or the damage. The application of the criterion of localization for incremental nonlinear laws (for which original mathematical studies were necessary) has led, among other results, to the explanation of the experimental evidence that the localization precedes the failure in dense geomaterials. In the case of loose soil, experiments show the presence of diffuse failure modes without localization. The "liquefaction" of loose sand saturated with water in the event of an earthquake is the most spectacular example. These failure modes remained for a long time without explanation, in the sense that they did not satisfy both the criteria of plasticity for geomaterials nor the criteria of the location. It follows that landslides in low slope and torrential mudflows (sometimes devastating: 161 dead in Italy in 1998) cannot be described by these criteria. In 1987, Felix Darve found a material instability criterion that was applicable in these situations: The stability condition of Hill-Mandel, linked to the sign of the second-order work. The introduction of these concepts has been very successful, as they are now internationally used to describe diffuse failure. This set of concepts and tools has allowed to completely rethink the notions of fracture and mechanical instability in nonviscous solids in a wider and more rational context, including for instance avalanches of grains in discrete mechanics.

Natural hazards have been, until recently, treated with empirical methods. The development of tools and methods for describing the mechanical behavior of nonassociated and triphasic geomaterials allow to better model and understand these natural phenomena and to forecast them in order to intervene with appropriate consolidation works. In domains where multi-scale and multi-phase aspects play a central role, the School of geomechanics of Grenoble occupies a leading position internationally.

The committee, entrusted by the

"Fondazione Levi-Civita"

and the Scientific Committee of the

International Research Center MEMOCS

with the responsibility of awarding the

International Levi-Civita Prize

unanimously propose Professor Félix Darve as winner of the 2012 edition. 